\title{
Incorporação do Impacto da Rede de Reservatórios Superficiais Artificiais de Caráter Intranual na Modelagem Hidrológica Chuva-Vazão
}

\author{
Alan Michell Barros Alexandre*; Francisco de Assis de Souza Filho*; José Nilson Beserra Campos* \\ alan-michell@hotmail.com; assis@ufc.br; nilson@ufc.br
}

Recebido: 20/04/11 - revisado: 10/09/11 - aceito: 24/10/12

\begin{abstract}
RESUMO
A capacidade que um modelo hidrológico possui para descrever os processos envolvidos na transformação de chuvavazão depende de suas premissas, estrutura e formulações utilizadas. Modelos do tipo concentrado são bastante atrativos, no entanto, as simplificações matemáticas utilizadas podem gerar erros no caso da bacia representada possuir características muito heterogêneas decorrentes de características naturais ou de atividade antrópica. O regime fluvial no semi-árido do nordeste brasileiro sofreu modificações devidas a construção de reservatórios artificiais superficiais, em sua grande maioria pequenos reservatórios de caráter intranual. Esses pequenos reservatórios tornam difícil a modelagem. Propõe-se nesse artigo a inserção de uma rotina com vistas a incorporar explicitamente a representação da pequena açudagem utilizando como base a estrutura do modelo SMAP. Esta representação se faz através da inclusão de um reservatório no modelo matemático com as características de operação representativas do comportamento da pequena açudagem. A dimensão deste reservatório é um parâmetro calibrável $\left(h_{R P A}\right)$ com vistas a identificação do efeito destes regularização intranual. O modelo proposto, SMAPRPA, constitui uma ampliação do modelo SMAP em sua versão mensal, por tanto os resultados determinados a partir da componente RPA torna o desempenho do modelo melhor e fisicamente mais realista quando comparado ao desempenho do SMAPm. Logo, nos casos em que os açudes presentes na bacia hidrográfica não produzem variação consideráveis no hidrograma, o parâmetro " $h_{R P A}$ " é nulo e o funcionamento do SMAP-RPA assume o mesmo do SMAPm. Com o objetivo de verificar a validade do modelo proposto foi desenvolvido um estudo de caso com a formulação de dois cenários segundo as séries de vazões e as características de 18 bacias hidrográficas localizadas no Estado do Ceará. Os resultados comprovam a eficácia da representação da pequena açudagem e o conseqüente ganho de eficiência nos ajustes das séries observadas e calculadas. Observou-se neste trabalho importante efeito de escala sendo as bacias mais afetadas pela pequena açudagem as com área de drenagem inferiores a $5.000 \mathrm{~km}^{2}$. Para bacias de maior porte o impacto desta pequena açudagem não é detectada a partir do modelo tornando assim o parâmetro " $h_{R P A}$ " nulo.
\end{abstract}

Palavras-chave: Modelagem hidrológica; reservatórios intranuais; SMAP-RPA.

\section{INTRODUCÃ̃O}

As modificações do uso e ocupação do solo modificam a ocorrência dos processos hidrológicos em uma bacia hidrográfica produzindo alterações ou impactos no regime fluvial. Avaliar o impacto destas modificações é essencial para subsidiar o gerenciamento e uso sustentável dos recursos hídricos.

Os modelos hidrológicos nasceram como resposta a esta necessidade, procurando representar os diferentes processos hidrológicos com vistas a compreensão e a avaliação do sistema Bacia Hidrográfica integrando os componentes causais da natureza e os fatores antrópicos.

*Departamento de Engenharia Hidráulica e Ambiental - Universidade Federal do Ceará
A capacidade que um modelo possui para descrever os processos envolvidos depende de suas premissas, estrutura e formulações utilizadas. A existência de um modelo para simular um processo não garante que os resultados obtidos sejam adequados e as incertezas envolvidas geralmente se relacionam com: a capacidade do modelo em representar os processos, a limitada medida e representação das variáveis de entradas e a variabilidade dos parâmetros para representar o sistema (WAGENER et. al., 2004).

Quando se representa o processo de transformação chuva-vazão através modelos concentrados uma das fontes de incertezas mais destacadas são inerentes as próprias suposições do modelo, o qual representa os processos hidrológicos por valores médios em termos espaciais das variáveis, obtendo assim, de modo geral uma formulação mais simples 
Incorporação do Impacto da Rede de Reservatórios Superficiais Artificiais de Caráter Intranual na Modelagem Hidrológica Chuva-Vazão

e um menor número de parâmetros quando comparados aos modelos distribuídos. Modelos com esse tipo de estrutura são bastante atrativos pela fácil operação devido ao menor número de variáveis de entrada, fácil calibração, entre outras vantagens.

No entanto, as simplificações matemáticas utilizadas para representar os processos de transformação da chuva-vazão podem gerar erros grosseiros no caso da bacia representada ter características muito heterogêneas, podendo assim comprometer os estudos nos quais essa ferramenta se faz necessária como: para extensão de séries hidrológicas em locais com poucas informações, dimensionamento e planejamento de desenvolvimento numa bacia hidrográfica, previsão de vazão com base em modificações naturais e antrópicas da bacia hidrográfica.

Nesse estudo considera-se como principal modificação antrópica para o semi-árido Nordestino a construção de reservatórios artificiais superficiais, em sua grande maioria de caráter intranual. Estes tornam sobre maneira difícil a modelagem hidrológica devido, entre outras causas, ao nível de informação necessária para realizá-la. Uma dificuldade a mais é a variação na rede destes reservatórios em uma bacia devido ao rompimento de alguns destes e construção de novos açudes ao longo do tempo.

A situação atual da densidade de pequenos reservatórios no Nordeste Brasileiro pode ser verificada no estudo realizado por FUNCEME (2007). Neste estudo foram levantados os espelhos d'água de todo o Brasil com área superior a 20 hectares e 5 hectares para o Nordeste. Tal estudo apresenta o Ceará como o Estado com maior número de espelhos d'água do Nordeste, com um total de 5.598 espelhos d'água com área superior a 5 hectares, dos quais $87,92 \%$ são do tipo Artificial, destes menos de 200 tem capacidade relevante de regularização plurianual.

Portanto, torna-se conveniente o estudo de técnicas de representação de pequenos reservatórios intranuais em modelos hidrológicos chuva-vazão que possibilitem a análise do impacto dos mesmos.

O presente estudo propõe o uso de modelagem hidrológica de estrutura concentrada com a utilização de uma rotina específica para análise da influência da pequena açudagem no processo de transformação chuva-vazão. Construindo assim uma ferramenta acessível que viabilize o gerenciamento de bacias hidrográficas submetidas a efeito significativo do armazenamento intranual.

Assim, tem-se por objetivo: i) Proposição de metodologia de representação do impacto da pequena açudagem em modelo chuva-vazão de estrutura concentrada; e ii) Análise da validade da meto- dologia proposta, através da capacidade de representação da pequena açudagem e do desempenho do modelo modificado.

\section{MODELOS HIDROLÓGICOS}

\section{O Modelo SMAP}

O modelo SMAP (Soil Moisture Accounting Procedure) é um modelo determinístico de simulação hidrológica do tipo transformação chuva-vazão. Este foi originalmente desenvolvido para intervalo de tempo diário (LOPES et. al., 1981) e posteriormente apresentado nas versões horária e mensal, adaptando-se algumas modificações em sua estrutura.

Neste estudo utilizou-se como base a estrutura da versão mensal (ver Figura 1), doravante chamado de SMAPm, para inserção em sua estrutura de um reservatório virtual representativo dos efeitos dos reservatórios superficiais artificiais.

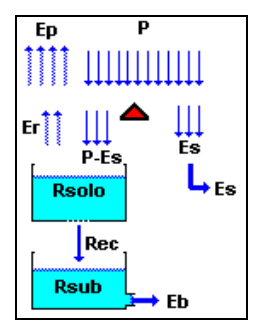

Figura 1 - Estrutura do SMAP em sua versão
mensal (SMAPm)

O SMAPm é constituído de dois reservatórios matemáticos, cujas variáveis de estado são atualizadas a cada mês da forma:

$$
\begin{aligned}
& \operatorname{Rsolo}_{(\mathrm{i})}=\operatorname{Rsolo}_{(\mathrm{i}-1)}+\mathrm{P}_{(\mathrm{i})}-\mathrm{Es}_{(\mathrm{i})}-\mathrm{Er}_{(\mathrm{i})}-\operatorname{Rec}_{(\mathrm{i})} \\
& \operatorname{Rsub}_{(\mathrm{i})}=\operatorname{Rsub}_{(\mathrm{i}-1)}+\operatorname{Rec}_{(\mathrm{i})}-\mathrm{Eb}_{(\mathrm{i})}
\end{aligned}
$$

onde: Rsolo, reservatório que representa a camada superior do solo; Rsub, reservatório que representa a camada inferior do solo (subterrânea); P, precipitação; Es, escoamento superficial; Er, evapotranspiração real; Rec, recarga do reservatório subterrâneo e Eb, escoamento de base. Todas variáveis em milímetros.

Com a inicialização destas variáveis calculadas por:

Rsolo $_{(\mathrm{i}=1)}=$ Tuin x Sat 
$\operatorname{Rsub}_{(\mathrm{i}=1)}=\mathrm{Ebin} /(1-\mathrm{Kk}) / \operatorname{Ad} \times 2.630$

onde: Tuin, taxa de umidade do solo inicial; Sat, nível de saturação do solo (mm); Ebin, escoamento de base inicial; Kk, deplecionamento do escoamento de base (meses); Ad, área da bacia hidrográfica $\left(\mathrm{km}^{2}\right)$.

As demais variáveis são calculadas da seguinte forma:

$$
\begin{aligned}
& \mathrm{Es}_{(\mathrm{i})}=\left(\mathrm{Tu}_{(\mathrm{i})}\right)^{\mathrm{PEs}} \times \mathrm{P}_{(\mathrm{i})} \\
& \operatorname{Er}_{(\mathrm{i})}=\mathrm{Tu}_{(\mathrm{i})} \times \mathrm{Ep}_{(\mathrm{i})} \\
& \operatorname{Rec}_{(\mathrm{i})}=\operatorname{CRec} \times\left(\mathrm{Tu}_{(\mathrm{i})}\right)^{4} \times \operatorname{Rsolo}_{(\mathrm{i})} \\
& \mathrm{Eb}_{(\mathrm{i})}=(1-\mathrm{Kk}) \times \operatorname{Rsub}_{(\mathrm{i})} \\
& \text { Sendo: } \mathrm{Tu}_{(\mathrm{i})}=\operatorname{Rsolo}_{(\mathrm{i})} / \text { Sat }
\end{aligned}
$$

onde: Tu, taxa de umidade do solo; PEs, parâmetro que controla o escoamento superficial; Ep, evaporação potencial (mm); Crec, capacidade de recarga do reservatório subterrâneo $(\mathrm{mm})$.

O modelo possui 4 parâmetros calibráveis: Sat - Capacidade de saturação do solo (mm); PEs Parâmetro que controla o escoamento superficial (ad.); CRec - Coeficiente de recarga do reservatório subterrâneo (ad.) e K - Constante de recessão do reservatório subterrâneo $\left(\mathrm{mes}^{-1}\right)$.

Para a determinação dos diferentes escoamentos faz-se necessário os seguintes ajustes: $\mathrm{Kk}=$ $(0,5)^{(1 / \mathrm{K})}$, onde $\mathrm{Kk}$ expressa em meses o tempo em que a vazão básica é reduzida a metade de seu valor inicial; CRec e Tu são multiplicados por 100.

O modelo contém uma rotina de atualização previa do teor de umidade que a cada intervalo de tempo acrescenta uma parcela de chuva do mês, de forma a utilizar o teor de umidade médio do mês em questão. Segundo os autores, essa rotina melhora sensivelmente os resultados, principalmente em regiões de grande variabilidade no regime pluviométrico. equação:

Finalmente o cálculo da vazão é dado pela

$\mathrm{Q}=\left(\mathrm{ES}_{(\mathrm{i})}+\mathrm{Eb}_{(\mathrm{i})}\right) \times \mathrm{Ad} / 2.630$

Os dados de entrada do modelo são: a série mensal de chuva $(\mathrm{P})$ e a evaporação potencial mensal (Ep). Para a calibração do modelo faz-se necessá- rio o uso da série de vazões médias mensais observadas $(\mathrm{Qm})$.

A medida de eficiência do ajuste do modelo utilizada foi a proposta por Nash e Sutcliffe (1970):

$\mathrm{E}_{\mathrm{NS}}(\%)=\left[1-\frac{\sum_{\mathrm{i}=1}^{\mathrm{n}}\left(\mathrm{Qobs}_{(\mathrm{i})}-\mathrm{Qcalc}_{(\mathrm{i})}\right)^{2}}{\sum_{\mathrm{i}=1}^{\mathrm{n}}\left(\mathrm{Qobs}_{(\mathrm{i})}-\mathrm{Qmed}^{2}\right.}\right] x 100$

onde: $\operatorname{Qobs}_{(\mathrm{i})}$, vazão observada; Qcalc $(\mathrm{i})$, vazão calculada; $\operatorname{Qmed}_{(\mathrm{i})}$, vazão média observada; $i$, intervalo de tempo; n, número de intervalos de tempo. Os valores de vazão são medidos $\mathrm{em}^{3} / \mathrm{s}$. Os valores de $\mathrm{E}_{\mathrm{NS}}$ variam de $100 \%$ (melhor ajuste) a menos infinito.

\section{O Modelo proposto: SMAP-RPA}

O estudo ora em desenvolvimento visa o análise dos efeitos na geração de vazões através de modelo chuva deflúvio em ambiente com altos índices de evaporação, com pronunciada sazonalidade do regime de chuvas (precipitações concentradas em 3 a 6 meses do ano) e bacias hidrográficas com grande número de reservatórios intranuais.

Os reservatórios intranuais possuem esse caráter basicamente por suas pequenas dimensões e alto grau de evaporação da região. Sua dinâmica nas bacias hidrográficas do semi-árido nordestino é de enchimento no período que há escoamento superficial, em geral entre janeiro e junho. Dependente sobre maneira da quantidade de água precipitada no início do ano, estes reservatórios podem apresentar vertimento já nos meses entre fevereiro e abril permanecendo cheios até os meses de maio e junho ou chegar ao fim da estação chuvosa apenas parcialmente cheios. Neste geoambiente, no segundo semestre do ano tais reservatórios perdem rapidamente grandes volumes de água devido aos altos níveis de evaporação registrados e o uso no período de vazões baixas. As vazões mínimas são freqüentemente nulas caracterizando a intermitência do regime fluvial, o que faz com que estes reservatórios em 3 ou 4 meses já se apresentem totalmente secos.

Já os reservatórios interanuais possuem a capacidade de armazenar água por mais de um ano hidrológico. Sua dinâmica de armazenamento de água para os períodos de escassez e/ou perenização de rios torna complexa sua operação devido às diversas variáveis envolvidas, dificultando assim a inserção de mais de um reservatório com essas características na modelagem hidrológica. A metodologia 
Incorporação do Impacto da Rede de Reservatórios Superficiais Artificiais de Caráter Intranual na

Modelagem Hidrológica Chuva-Vazão

utilizada em Payan et. al. (2008), que versa na inserção de um reservatório virtual na estrutura do modelo hidrológico concentrado com as dimensões e regra de operação idêntica a do maior reservatório superficial artifical localizado na bacia em estudo, não satisfaz as necessidades do semi-árido nordestino.

Portanto, observando as dinâmicas descritas acima, propõe-se neste estudo a representação dos açudes intranuais, localizados a montante da estação fluviométrica em que se pretende calibrar o modelo chuva-vazão (MCV), através da inserção de mais um reservatório matemático (RPA) na estrutura do modelo SMAP em sua versão mensal, o qual tornará explicita a dinâmica dos reservatórios intranuais na modelagem hidrológica. A estrutura desse modelo, doravante denominado SMAP-RPA, pode ser observada na Figura 2.

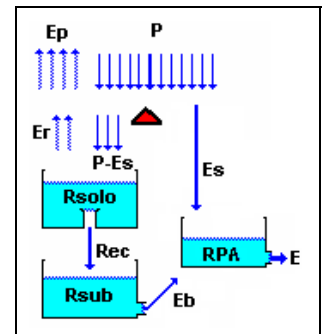

Figura 2 - Estrutura do SMAP-RPA

A modelagem chuva-vazão utilizando o reservatório matemático representativo dos açudes intranuais (RPA) recebe o escoamento supeficial (Es) e subterrâneo (Eb) e acumula estes valores em cada passo de tempo durante o período com escoamento, onde os volumes vertidos deste RPA são transformados em escoamento final (Ef). O volume do RPA e o cálculo do escoamento final dependem do parâmetro que representa a altura máxima do RPA $\left(h_{\mathrm{RPA}}\right)$, portanto este parâmetro deve ser calibrado, por representar uma característica intrínseca da bacia hidrográfica em estudo.

Assim, o SMAP-RPA possui o cálculo do escoamento superficial e subterrâneo da mesma forma do SMAPm. A partir deste passos o SMAP-RPA segue a seguinte formulação:

Para o primeiro semestre:

$\mathrm{RPA}_{(\mathrm{i})}=\mathrm{ES}_{(\mathrm{i})}+\mathrm{Eb}_{(\mathrm{i})}+\mathrm{RPA}_{(\mathrm{i}-1)}-\mathrm{Ef}_{(\mathrm{i}-1)}$

onde: RPA, reservatório matemático representativo dos açudes intranuais; Es, escoamento supeficial; Eb, escoamento subterrâneo; Ef, escoamento final. Todas variáveis em milímetros.

Se: $\mathrm{RPA}_{(\mathrm{i})}-\mathrm{h}_{\mathrm{RPA}}>0$

onde: $\mathrm{h}_{\mathrm{RPA}}$, capacidade máxima do reservatório RPA (mm).

Caso contrário:

$\mathrm{Ef}_{(\mathrm{i})}=0$

Para o segundo semestre:

$\operatorname{RPA}_{(\mathrm{i})}=0$

$\mathrm{Ef}_{(\mathrm{i})}=\mathrm{ES}_{(\mathrm{i})}+\mathrm{Eb}_{(\mathrm{i})}$

Desta forma, o SMAP-RPA quando tem seu valor de " $h_{\mathrm{RPA}}$ " igualado a zero funciona exatamente igual ao SMAPm. Portanto, espera-se que com a representação dos reservatórios intranuais presentes na bacia hidrográfica em estudo através da calibração do parâmetro " $h_{\text {RPA }}$ " os resultados da eficiência dos ajustes entre as séries de vazões observadas e calculadas sejam iguais ou melhores que os calculados pelo SMAPm nas mesmas circunstâncias.

Devido à possibilidade do reservatório RPA também representar de forma indireta alguns reservatórios de caráter interanuais serão realizados experimentos para verificação desta assertiva.

Utilizou-se neste estudo, na medida do possível, o ano hidrológico da região como referência, visando iniciar a calibração pelos meses mais secos, pois nesse período a umidade do solo e a vazão básica estão em seus valores mínimos, não sendo necessária assim a incorporação destes parâmetros na calibração.

\section{CARACTERIZAÇÃO DA REGIÃO DE APLICAÇÃO DO MODELO PROPOSTO}

Utiliza-se como base de estudo área de contribuição de 18 estações fluviométricas localizadas no estado do Ceará. O Quadro 1 apresenta as características das estações, e suas respectivas bacias de contribuição; e na Figura 3 é apresentada a sua distribuição espacial.

Em sua maioria as bacias em estudo possuem atualmente um grande número de pequenos e 
médios reservatórios superficiais artificiais. Esta identificação tem como base o trabalho realizado por FUNCEME (2007), onde foram levantados através de imagem de satélite todos os espelhos d'água do estado com área superior a 5 hectares, utilizando imagem de satélite dos anos de 2005 e 2006.

Visando facilitar o entendimento do leitor, consideraremos nesse estudo os reservatórios com capacidade de armazenamento superior a $10,0 \mathrm{hm}^{3}$ como reservatórios estratégicos e os demais reservatórios como pequena açudagem, seguindo assim a classificação utilizada no "Plano Estadual de Recursos Hidricos do Cearâ" em SRH-CE (1992).

Os reservatórios considerados estratégicos foram caracterizados com os dados de volume e ano de término das construções a partir do cadastro do "Atlas Eletrônico dos Recursos Hídricos do Cearâ" localizado no sítio da internet: http://atlas.srh.ce.gov.br. Os demais espelhos d'água localizados nas bacias tiveram a capacidade máxima de acumulação estimada através da metodologia de regressão apresentada em SRH-CE (1992). Tal metodologia apresenta equações do tipo exponencial para diferentes combinações entre os tipos de relevos e níveis de ramificação da hidrografia, estas equações utilizam com variável explanatória a área da bacia hidráulica dos reservatórios.

Os valores totais acumulados das áreas das bacias hidráulicas e das capacidades máximas de armazenamento dos reservatórios superficiais artificiais por bacia hidrográfica podem ser observados no Quadro 2. A distribuição de freqüência destas áreas e volumes em classes é apresentada no Quadro 3.

Com o objetivo de analisar o nível de saturação das bacias hidrográficas com relação aos reservatórios superficiais artificiais nestas presentes calculou-se dois indicadores: i) a relação entre a área total de espelhos d'água ou bacia hidráulica com área da bacia hidrográfica; e ii) a relação entre o volume total armazenável nos reservatórios com o volume anual escoado na bacia hidrográfica. Tal análise pode ser observada no Quadro 4.

No estudo de Alexandre (2005) foram realizadas calibração e regionalização dos parâmetros dos SMAPm para 22 bacias hidrográficas no estado do Ceará. Em tal estudo o coeficiente de recarga (CRec) do reservatório virtual que representa o meio subterrâneo (Rsub) foi considerado nulo, pois as bacias se encontram sobre um embasamento cristalino. A constante de recessão $(\mathrm{K})$ apresentou-se pouco sensível a diferentes tipos de Função Objetivo testadas, sendo, portanto objeto de calibração manual. Assim, na calibração automática, que visa à maximização da Função Objetivo que utiliza a equação de eficiência proposta por Nash e Sutcliffe (1970), foi utilizada apenas para os parâmetros "Sat" e "PEs". Este procedimento será utilizado como referência para o presente estudo.

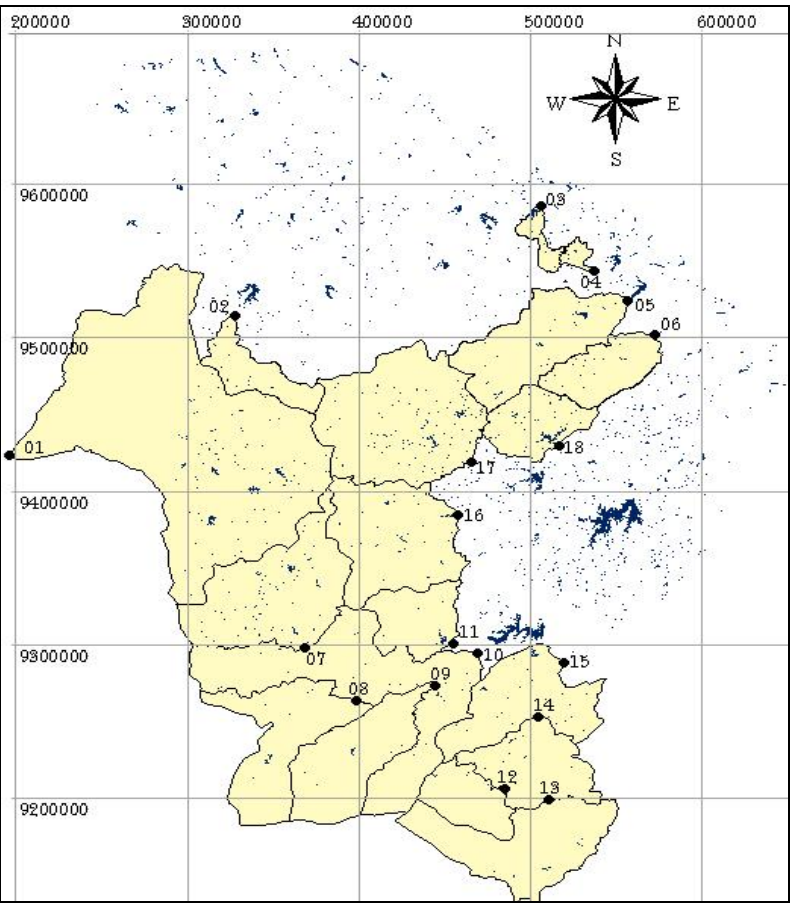

Figura 3 - Distribuição espacial das estações fluviométricas utilizadas no estudo.

Para os dados de entrada do modelo foram utilizadas as séries precipitação diárias das diversas estações com área de influência na bacia hidrográfica ponderadas pelo método de Thiessen e em seguida realizada a totalização mensal, os dados de precipitação foram coletados a partir dos dados disponibilizados pela Agência Nacional de Águas ANA e pela Fundação Cearense de Meteorologia e Recursos Hídricos - FUNCEME. Os dados de evaporação utilizados provêm das Normais Climatológicas dos anos 1961 a 1990, apresentadas pelo Instituto Nacional de Meteorologia - INMET em INMET(1992) devido a facilidade de aquisição destes dados.

A rede de estações com dados de Normais Climatológicas de evaporação pode ser considerada esparsa, no entanto a pequena variabilidade espacial destes dados para o estado do Ceará torna-os suficientemente representativos. Essa assertiva é corroborada pelo estudo realizado por Carvalho e Reis Jr. (2008), no qual verificou que para o estado do Ceará a modelagem chuva-vazão através de um modelo 
Incorporação do Impacto da Rede de Reservatórios Superficiais Artificiais de Caráter Intranual na Modelagem Hidrológica Chuva-Vazão

Quadro 1 - Caracterização das estações fluviométricas utilizadas no estudo.

\begin{tabular}{|l|l|c|c|c|c|c|}
\hline ID & Código & Nome & Rio & $\begin{array}{c}\text { Área Bacia } \\
\left.\text { Hidrográfica } \mathbf{( k m}^{\mathbf{}}\right)\end{array}$ & $\begin{array}{c}\text { Vazão Média } \\
\text { Mensal }\left(\mathbf{m}^{\mathbf{3}} / \mathbf{s}\right)\end{array}$ & $\begin{array}{c}\text { Período } \\
\mathbf{d e} \mathbf{d a d o s}\end{array}$ \\
\hline 01 & 34750000 & Fazenda Boa Esperança & Poti & $18.339,5$ & 34,06 & $1965-2005$ \\
\hline 02 & 35210000 & Fazenda Cajazeiras & Acaraú & $1.642,6$ & 6,46 & $1963-2006$ \\
\hline 03 & 35650000 & Sítios Novos & São Gonçalo & 453,9 & 2,91 & $1969-1978$ \\
\hline 04 & 35760000 & Baúl & Baúl & 244,9 & 2,11 & $1967-1973$ \\
\hline 05 & 35880000 & Chorozinho & Choró & $4.093,2$ & 14,30 & $1970-1993$ \\
\hline 06 & 35950000 & Cristais & Pirangi & $2.055,8$ & 5,51 & $1970-2006$ \\
\hline 07 & 36020000 & Arneiroz & Jaguaribe & $5.521,5$ & 5,67 & $1936-1981$ \\
\hline 08 & 36045000 & Malhada & Rch. Conceição & $3.958,5$ & 2,90 & $1982-2005$ \\
\hline 09 & 36125000 & Sitio Poço Dantas & Bastiões & $3.746,1$ & 4,03 & $1968-2002$ \\
\hline 10 & 36160000 & Iguatúl & Jaguaribe & $20.608,9$ & 37,22 & $1937-2006$ \\
\hline 11 & 36180000 & Suassurana & Trussu & $2.027,2$ & 7,70 & $1969-1975$ \\
\hline 12 & 36210000 & Sítio Lapinha & Salgado & $1.755,9$ & 3,75 & $1985-2005$ \\
\hline 13 & 36250000 & Podimirim & Rch. dos Porcos & $4.372,0$ & 3,85 & $1973-2005$ \\
\hline 14 & 36270000 & Lavras Mangabeira & Salgado & $8.987,0$ & 24,71 & $1962-1996$ \\
\hline 15 & 36290000 & Icó & Salgado & $12.680,4$ & 26,78 & $1958-2005$ \\
\hline 16 & 36470000 & Senador Pompeu & Banabuiú & $4.838,3$ & 10,70 & $1921-2005$ \\
\hline 17 & 36520000 & Quixeramobim & Quixeramobim & $6.794,6$ & 14,36 & $1912-2005$ \\
\hline 18 & 36550000 & Boq.de Pedras Brancas & Jaguaribe & $2.011,3$ & 4,92 & $1946-1952$ \\
\hline
\end{tabular}

Quadro 2 - Caracterização dos reservatórios superficiais artificiais contidos atualmente nas bacias hidrográficas.

\begin{tabular}{|c|c|c|c|c|c|c|}
\hline \multirow[b]{2}{*}{ Estação } & \multicolumn{3}{|c|}{ Pequena açudagem } & \multicolumn{3}{|c|}{ Reservatórios estratégicos } \\
\hline & $\begin{array}{l}\text { Quantidade } \\
\quad \text { (und.) }\end{array}$ & $\begin{array}{c}\text { Área total das } \\
\text { bacias } \\
\text { hidráulicas (ha) }\end{array}$ & $\begin{array}{c}\text { Volume total } \\
\text { armazenável } \\
\left(\mathrm{hm}^{3}\right)\end{array}$ & $\begin{array}{l}\text { Quantidade } \\
\text { (und.) }\end{array}$ & $\begin{array}{c}\text { Área total das } \\
\text { bacias hidráulicas } \\
\text { (ha) }\end{array}$ & $\begin{array}{c}\text { Volume total } \\
\text { Armazenável } \\
\qquad\left(\mathrm{hm}^{3}\right)\end{array}$ \\
\hline 34750000 & 381 & $6.833,70$ & 145,35 & 5 & $6.289,82$ & 446,04 \\
\hline 35210000 & 81 & 926,69 & 17,45 & 2 & 430,37 & 38,00 \\
\hline 35650000 & 9 & 209,94 & 4,81 & 2 & $2.008,58$ & 137,01 \\
\hline 35760000 & 25 & 682,44 & 16,56 & - & - & - \\
\hline 35880000 & 116 & $1.777,20$ & 42,94 & 3 & $3.161,08$ & 377,60 \\
\hline 35950000 & 66 & $1.020,47$ & 22,47 & 1 & 352,99 & 28,90 \\
\hline 36020000 & 226 & $4.899,50$ & 128,84 & 4 & $2.247,15$ & 295,57 \\
\hline 36045000 & 27 & 498,09 & 12,05 & 2 & $1.032,49$ & 71,56 \\
\hline 36125000 & 27 & $1.017,86$ & 21,13 & 1 & 482,05 & 69,25 \\
\hline 36160000 & 396 & $7.309,11$ & 188,47 & 9 & $4.296,31$ & 503,54 \\
\hline 36180000 & 40 & 528,49 & 13,69 & 1 & $1.625,64$ & 301,00 \\
\hline 36210000 & 6 & 69,97 & 1,683 & 2 & 445,29 & 43,40 \\
\hline 36250000 & 26 & 990,01 & 18,64 & - & - & - \\
\hline 36270000 & 84 & $1.892,51$ & 40,55 & 4 & $1.278,80$ & 147,49 \\
\hline 36290000 & 235 & $3.868,49$ & 94,41 & 8 & $4.860,24$ & 338,39 \\
\hline 36470000 & 187 & $2.120,89$ & 54,10 & 4 & $1.459,84$ & 162,16 \\
\hline 36520000 & 411 & $6.244,29$ & 151,44 & 4 & $3.071,25$ & 267,78 \\
\hline 36550000 & 192 & $2.463,42$ & 57,69 & 2 & $4.623,87$ & 559,74 \\
\hline
\end{tabular}


Quadro 3 - Distribuição de freqüências dos reservatórios superficiais artificiais contidos atualmente nas bacias hidrográficas.

\begin{tabular}{|c|c|c|c|c|c|c|c|c|}
\hline \multirow{2}{*}{ Estação } & \multicolumn{4}{|c|}{ Área Bacia Hidráulica (ha) } & \multicolumn{4}{|c|}{ Volume máximo $\left(\mathrm{hm}^{3}\right)$} \\
\hline & 5 a 10 & 10 a 50 & 50 a 100 & $>100$ & $<1,0$ & 1,0 a 5,0 & 5,0 a 10,0 & $>10,0$ \\
\hline 34750000 & 194 & 162 & 16 & 13 & 355 & 24 & 1 & 5 \\
\hline 35210000 & 66 & 12 & 1 & 3 & 77 & 3 & 0 & 2 \\
\hline 35650000 & 3 & 5 & 0 & 2 & 8 & 0 & 0 & 2 \\
\hline 35760000 & 11 & 10 & 1 & 2 & 19 & 5 & 0 & 0 \\
\hline 35880000 & 71 & 37 & 6 & 4 & 106 & 9 & 0 & 3 \\
\hline 35950000 & 40 & 22 & 1 & 3 & 62 & 3 & 0 & 1 \\
\hline 36020000 & 99 & 107 & 12 & 11 & 201 & 20 & 4 & 4 \\
\hline 36045000 & 13 & 9 & 4 & 2 & 22 & 4 & 0 & 2 \\
\hline 36125000 & 13 & 9 & 3 & 2 & 20 & 5 & 1 & 1 \\
\hline 36160000 & 194 & 173 & 22 & 16 & 358 & 35 & 3 & 9 \\
\hline 36180000 & 31 & 7 & 1 & 1 & 38 & 1 & 0 & 1 \\
\hline 36210000 & 2 & 4 & 0 & 2 & 6 & 0 & 0 & 2 \\
\hline 36250000 & 11 & 12 & 1 & 1 & 23 & 2 & 0 & 0 \\
\hline 36270000 & 49 & 30 & 2 & 6 & 78 & 5 & 0 & 4 \\
\hline 36290000 & 152 & 71 & 5 & 14 & 219 & 13 & 2 & 8 \\
\hline 36470000 & 141 & 40 & 5 & 4 & 179 & 7 & 0 & 4 \\
\hline 36520000 & 255 & 137 & 12 & 10 & 389 & 21 & 0 & 4 \\
\hline 36550000 & 111 & 76 & 4 & 2 & 186 & 5 & 0 & 2 \\
\hline
\end{tabular}

Quadro 4 - Indicadores de nível de saturação atual das bacias hidrográficas com relação aos reservatórios superficiais artificiais.

\begin{tabular}{|c|c|c|c|c|c|c|}
\hline Estação & $\begin{array}{c}\text { Bacia } \\
\text { hidrográfica } \\
\left(\mathbf{k m}^{2}\right)\end{array}$ & $\begin{array}{c}\text { Área total das } \\
\text { bacias } \\
\text { hidráulicas }\left(\mathbf{k m}^{2}\right)\end{array}$ & $\begin{array}{l}\text { Percentual da } \\
\text { bacia } \\
\text { hidrográfica }\end{array}$ & $\begin{array}{c}\text { Volume } \\
\text { armazenável } \\
\left(\mathbf{h m}^{3}\right)\end{array}$ & $\begin{array}{c}\text { Volume } \\
\text { anual } \\
\text { escoado } \\
\left(\mathbf{h m}^{3}\right)\end{array}$ & $\begin{array}{l}\text { Percentual do } \\
\text { volume escoa- } \\
\text { do }\end{array}$ \\
\hline 34750000 & $18.339,5$ & 131,24 & $0,72 \%$ & 591,39 & 1074,14 & $55 \%$ \\
\hline 35210000 & $1.642,6$ & 13,57 & $0,83 \%$ & 55,45 & 203,76 & $27 \%$ \\
\hline 35650000 & 453,9 & 22,19 & $4,89 \%$ & 141,82 & 91,84 & $154 \%$ \\
\hline 35760000 & 244,9 & 6,82 & $2,79 \%$ & 16,56 & 66,44 & $25 \%$ \\
\hline 35880000 & $4.093,2$ & 49,38 & $1,21 \%$ & 420,54 & 450,91 & $93 \%$ \\
\hline 35950000 & $2.055,8$ & 13,73 & $0,67 \%$ & 51,37 & 173,82 & $30 \%$ \\
\hline 36020000 & $5.521,5$ & 71,47 & $1,29 \%$ & 424,41 & 178,68 & $238 \%$ \\
\hline 36045000 & $3.958,5$ & 15,31 & $0,39 \%$ & 83,61 & 91,60 & $91 \%$ \\
\hline 36125000 & $3.746,1$ & 15,00 & $0,40 \%$ & 90,38 & 127,14 & $71 \%$ \\
\hline 36160000 & $20.608,9$ & 116,05 & $0,56 \%$ & 692,01 & 501,21 & $138 \%$ \\
\hline 36180000 & $2.027,2$ & 21,54 & $1,06 \%$ & 314,69 & 242,78 & $130 \%$ \\
\hline 36210000 & $1.755,9$ & 5,15 & $0,29 \%$ & 45,08 & 118,10 & $38 \%$ \\
\hline 36250000 & $4.372,0$ & 9,90 & $0,23 \%$ & 18,64 & 121,24 & $15 \%$ \\
\hline 36270000 & $8.987,0$ & 31,71 & $0,35 \%$ & 188,04 & 779,26 & $24 \%$ \\
\hline 36290000 & $12.680,4$ & 87,29 & $0,69 \%$ & 432,80 & 844,64 & $51 \%$ \\
\hline 36470000 & $4.838,3$ & 35,81 & $0,74 \%$ & 216,26 & 337,33 & $64 \%$ \\
\hline 36520000 & $6.794,6$ & 93,16 & $1,37 \%$ & 419,22 & 452,72 & $93 \%$ \\
\hline 36550000 & $2.011,3$ & 70,87 & $3,52 \%$ & 617,43 & 155,29 & $398 \%$ \\
\hline
\end{tabular}


Incorporação do Impacto da Rede de Reservatórios Superficiais Artificiais de Caráter Intranual na Modelagem Hidrológica Chuva-Vazão

Quadro 5 - Capacidade de armazenamento e valores equivalentes do parâmetro " $h_{R P A}$ " para os reservatórios contidos nas bacias hidrográficas no período de calibração do modelo.

\begin{tabular}{|c|c|c|c|c|c|c|c|}
\hline \multirow[b]{2}{*}{ Estação } & \multicolumn{2}{|c|}{ Pequena açudagem } & \multirow{2}{*}{$\begin{array}{c}\text { Ano de } \\
\text { construção } \\
\text { do } 1^{\circ} \text { reservató- } \\
\text { rio estratégico }\end{array}$} & \multicolumn{2}{|c|}{ Reservatórios estratégicos } & \multicolumn{2}{|c|}{ Total armazenável } \\
\hline & $\begin{array}{c}\text { Volume } \\
\text { Armazenável } \\
\left(\mathrm{hm}^{3}\right) \\
\end{array}$ & $\begin{array}{c}\mathbf{h}_{\mathrm{RPA}} \\
\text { equivalente } \\
(\mathrm{mm}) \\
\end{array}$ & & $\begin{array}{c}\text { Volume } \\
\text { Armazenável } \\
\left(\mathrm{hm}^{3}\right) \\
\end{array}$ & $\begin{array}{c}\mathbf{h}_{\mathrm{RPA}} \\
\text { equivalente } \\
(\mathrm{mm}) \\
\end{array}$ & $\begin{array}{c}\text { Volume } \\
\left(\mathrm{hm}^{3}\right)\end{array}$ & $\begin{array}{c}\mathbf{h}_{\mathrm{RPA}} \\
\text { equivalente } \\
(\mathrm{mm}) \\
\end{array}$ \\
\hline 34750000 & 145,35 & 7,93 & 1980 & 446,04 & 24,32 & 591,39 & 32,25 \\
\hline 35210000 & 17,45 & 10,62 & 1980 & 38,00 & 23,13 & 55,45 & 33,76 \\
\hline 35650000 & 4,81 & 10,60 & 1921 & 11,01 & 24,26 & 15,82 & 34,85 \\
\hline 35760000 & 16,56 & 67,62 & - & 0,00 & 0,00 & 16,56 & 67,62 \\
\hline 35880000 & 42,94 & 10,49 & 1934 & 143,00 & 34,94 & 185,94 & 45,43 \\
\hline 35950000 & 22,47 & 10,93 & 1998 & 28,90 & 14,06 & 51,37 & 24,99 \\
\hline 36020000 & 128,84 & 23,33 & 1954 & 51,91 & 9,40 & 180,75 & 32,74 \\
\hline 36045000 & 12,05 & 3,04 & 1958 & 71,56 & 18,08 & 83,61 & 21,12 \\
\hline 36125000 & 21,13 & 5,64 & 1999 & 0,00 & 0,00 & 21,13 & 5,64 \\
\hline 36160000 & 188,47 & 9,15 & 1954 & 306,48 & 14,87 & 494,95 & 24,02 \\
\hline 36180000 & 13,69 & 6,75 & 1996 & 0,00 & 0,00 & 13,69 & 6,75 \\
\hline 36210000 & 1,68 & 0,96 & 1982 & 28,78 & 16,39 & 30,46 & 17,35 \\
\hline 36250000 & 18,64 & 4,26 & - & 0,00 & 0,00 & 18,64 & 4,26 \\
\hline 36270000 & 40,55 & 4,51 & 1982 & 65,96 & 7,34 & 106,51 & 11,85 \\
\hline 36290000 & 94,41 & 7,45 & 1932 & 245,67 & 19,37 & 340,08 & 26,82 \\
\hline 36470000 & 54,10 & 11,18 & 1987 & 162,16 & 33,52 & 216,26 & 44,70 \\
\hline 36520000 & 151,44 & 22,29 & 1960 & 267,78 & 39,41 & 419,22 & 61,70 \\
\hline 36550000 & 57,69 & 28,68 & 1906 & 125,69 & 62,49 & 183,38 & 91,17 \\
\hline
\end{tabular}

conceitual possui comportamento semelhante utilizando dados de ETP baseados nas Normais Climatológicas ou calculada por métodos mais elaborados que consideram um maior número de variáveis climáticas em seus cálculos no passo de tempo diário.

Para a calibração do modelo SMAP-RPA foram utilizados os dados de vazões diária disponibilizados pela ANA, com posterior cálculo das médias mensais para as 18 estações fluviométricas selecionadas neste estudo.

Analisando as séries de dados de vazão e o ano de construção dos reservatórios estratégicos percebe-se que vários destes não haviam sido construídos no período estudado, ou apenas 1-2 anos do período total de calibração estão sob a influência destes reservatórios. O que nos leva a desconsiderar os volumes armazenados nos reservatórios construídos em anos posteriores aos das séries estudadas.

Já para os pequenos reservatórios essa consideração de cenários com datas estabelecidas tornase um pouco mais complexa a tentativa de divisão da série de vazões devida ausência de dados referentes aos espelhos d'água em períodos anteriores ao estudo realizado pela FUNCEME (2007). Sabe-se que a construção de pequenos reservatórios teve um grande impulso a partir dos anos 60, imposto pela política de mitigação dos efeitos da seca praticados pelo governo federal e estadual. Somente no final do século XX o efeito da pequena açudagem em uma região hidrográfica passou a ser analisado cientificamente. Por tanto, para efeito de comparação e análise dos resultados os dados atuais referentes a pequena açudagem nas bacias foi considerado constante para toda série de calibração.

O Quadro 5 apresenta o volume armazenável para os pequenos reservatórios e para os reservatórios estratégicos com influência na série de vazões, neste quadro também é estimado o valor equivalente do parâmetro " $\mathrm{h}_{\mathrm{RPA}}$ " no caso hipotético de todo o volume de armazenamento dos reservatórios superficiais artificiais serem retirados do volume escoado anual na bacia hidrográfica. Outros valores de " $h_{\mathrm{RPA}}$ " e sua equivalência em valores de capacidade máxima de armazenamento nos reservatórios contidos na bacia em estudo podem ser observados na Quadro 6.

Os valores de volume armazenável apresentados no Quadro 5 foram calculados através de modelos de regressão do tipo potencial os quais levam em consideração a dimensão do espelho d'água do reservatório, a localização deste em relação a ramificação do rio e a classificação do relevo. Tal metodo- 
Quadro 6 - Capacidade máxima de armazenamento nos reservatórios contidos nas bacias hidrográficas e suas respectivas equivalência para diferentes valores do parâmetro " $h_{\text {RPA }}$ ".

\begin{tabular}{|l|c|c|c|c|c|c|c|c|c|c|}
\hline \multirow{2}{*}{ Estação } & \multicolumn{10}{|c|}{ Capacidade de Armazenamento Equivalente $\left(\mathbf{h m}^{3}\right)$} \\
\cline { 2 - 12 } & $\mathbf{h}_{\text {RPA }}=\mathbf{5}$ & $\mathbf{h}_{\text {RPA }}=\mathbf{1 0}$ & $\mathbf{h}_{\mathbf{R P A}}=\mathbf{1 5}$ & $\mathbf{h}_{\mathbf{R P A}}=\mathbf{2 0}$ & $\mathbf{h}_{\mathbf{R P A}}=\mathbf{2 5}$ & $\mathbf{h}_{\mathbf{R P A}}=\mathbf{3 0}$ & $\mathbf{h}_{\mathbf{R P A}}=\mathbf{3 5}$ & $\mathbf{h}_{\mathbf{R P A}}=\mathbf{4 0}$ & $\mathbf{h}_{\mathbf{R P A}}=\mathbf{4 5}$ & $\mathbf{h}_{\mathbf{R P A}}=\mathbf{5 0}$ \\
\hline 34750000 & 91,70 & 183,40 & 275,09 & 366,79 & 458,49 & 550,19 & 641,88 & 733,58 & 825,28 & 916,98 \\
\hline 35210000 & 8,21 & 16,43 & 24,64 & 32,85 & 41,07 & 49,28 & 57,49 & 65,70 & 73,92 & 82,13 \\
\hline 35650000 & 2,27 & 4,54 & 6,81 & 9,08 & 11,35 & 13,62 & 15,89 & 18,16 & 20,43 & 22,70 \\
\hline 35760000 & 1,22 & 2,45 & 3,67 & 4,90 & 6,12 & 7,35 & 8,57 & 9,80 & 11,02 & 12,25 \\
\hline 35880000 & 20,47 & 40,93 & 61,40 & 81,86 & 102,33 & 122,80 & 143,26 & 163,73 & 184,19 & 204,66 \\
\hline 35950000 & 10,28 & 20,56 & 30,84 & 41,12 & 51,40 & 61,67 & 71,95 & 82,23 & 92,51 & 102,79 \\
\hline 36020000 & 27,61 & 55,22 & 82,82 & 110,43 & 138,04 & 165,65 & 193,25 & 220,86 & 248,47 & 276,08 \\
\hline 36045000 & 19,79 & 39,59 & 59,38 & 79,17 & 98,96 & 118,76 & 138,55 & 158,34 & 178,13 & 197,93 \\
\hline 36125000 & 18,73 & 37,46 & 56,19 & 74,92 & 93,65 & 112,38 & 131,11 & 149,84 & 168,57 & 187,31 \\
\hline 36160000 & 103,04 & 206,09 & 309,13 & 412,18 & 515,22 & 618,27 & 721,31 & 824,36 & 927,40 & 1030,45 \\
\hline 36180000 & 10,14 & 20,27 & 30,41 & 40,54 & 50,68 & 60,82 & 70,95 & 81,09 & 91,22 & 101,36 \\
\hline 36210000 & 8,78 & 17,56 & 26,34 & 35,12 & 43,90 & 52,68 & 61,46 & 70,24 & 79,02 & 87,80 \\
\hline 36250000 & 21,86 & 43,72 & 65,58 & 87,44 & 109,30 & 131,16 & 153,02 & 174,88 & 196,74 & 218,60 \\
\hline 36270000 & 44,94 & 89,87 & 134,81 & 179,74 & 224,68 & 269,61 & 314,55 & 359,48 & 404,42 & 449,35 \\
\hline 36290000 & 63,40 & 126,80 & 190,21 & 253,61 & 317,01 & 380,41 & 443,81 & 507,22 & 570,62 & 634,02 \\
\hline 36470000 & 24,19 & 48,38 & 72,57 & 96,77 & 120,96 & 145,15 & 169,34 & 193,53 & 217,72 & 241,92 \\
\hline 36520000 & 33,97 & 67,95 & 101,92 & 135,89 & 169,87 & 203,84 & 237,81 & 271,78 & 305,76 & 339,73 \\
\hline 36550000 & 10,06 & 20,11 & 30,17 & 40,23 & 50,28 & 60,34 & 70,40 & 80,45 & 90,51 & 100,57 \\
\hline
\end{tabular}

Quadro 7 - Intercomparação entre as características da modelagem do SMAPm e do SMAP-RPA

\begin{tabular}{|c|c|c|c|c|c|c|c|c|c|c|c|}
\hline \multirow[b]{2}{*}{ Estação } & \multicolumn{3}{|c|}{ SMAPm } & \multicolumn{5}{|c|}{ SMAP-RPA } & \multicolumn{3}{|c|}{ Erro Absoluto (\%) } \\
\hline & $\begin{array}{c}\text { Sat } \\
(\mathrm{mm}) \\
\end{array}$ & $\begin{array}{l}\text { PEs } \\
\text { (ad.) } \\
\end{array}$ & $\begin{array}{l}\mathbf{E}_{\mathrm{NS}} \\
(\%) \\
\end{array}$ & $\begin{array}{c}\text { Sat } \\
(\mathrm{mm}) \\
\end{array}$ & $\begin{array}{l}\text { PEs } \\
\text { (ad.) } \\
\end{array}$ & $\begin{array}{c}\mathbf{h}_{\mathbf{R P A}} \\
(\mathrm{mm}) \\
\end{array}$ & $\mathbf{E}_{\mathrm{NS}}(\%)$ & $\begin{array}{c}\text { Vol.RPA } \\
\left(\mathrm{hm}^{3}\right) \\
\end{array}$ & Sat & PEs & $\mathbf{E}_{\mathrm{NS}}$ \\
\hline 34750000 & $1.487,7$ & 2,22 & 82,87 & $1.487,7$ & 2,22 & 0,00 & 82,87 & 0,000 & 0,000 & 0,000 & 0,000 \\
\hline 35210000 & 763,1 & 2,32 & 74,26 & 784,9 & 2,10 & 11,96 & 74,37 & 19,649 & 2,857 & 9,483 & 0,148 \\
\hline 35650000 & $1.425,8$ & 3,26 & 87,16 & $1.508,8$ & 2,94 & 18,93 & 87,55 & 8,594 & 5,821 & 9,816 & 0,445 \\
\hline 35760000 & $1.176,4$ & 3,52 & 74,13 & $1.476,0$ & 2,22 & 55,78 & 75,36 & 13,662 & 25,468 & 36,932 & 1,632 \\
\hline 35880000 & $1.587,6$ & 2,70 & 85,58 & $1.596,9$ & 2,68 & 1,33 & 85,63 & 5,462 & 0,586 & 0,741 & 0,058 \\
\hline 35950000 & $1.592,8$ & 2,91 & 74,68 & $1.592,8$ & 2,91 & 0,00 & 74,68 & 0,000 & 0,000 & 0,000 & 0,000 \\
\hline 36020000 & 547,8 & 3,01 & 75,57 & 547,8 & 3,01 & 0,00 & 75,57 & 0,000 & 0,000 & 0,000 & 0,000 \\
\hline 36045000 & $1.630,4$ & 2,65 & 71,31 & $1.630,4$ & 2,65 & 0,00 & 71,31 & 0,000 & 0,000 & 0,000 & 0,000 \\
\hline 36125000 & $1.675,5$ & 3,04 & 83,86 & $1.702,1$ & 2,99 & 1,84 & 83,93 & 6,905 & 1,588 & 1,645 & 0,081 \\
\hline 36160000 & $1.187,7$ & 2,67 & 82,22 & $1.187,7$ & 2,67 & 0,00 & 82,22 & 0,000 & 0,000 & 0,000 & 0,000 \\
\hline 36180000 & $1.316,5$ & 3,41 & 89,88 & $1.334,3$ & 3,27 & 9,41 & 89,99 & 19,084 & 1,352 & 4,106 & 0,122 \\
\hline 36210000 & $3.116,0$ & 3,41 & 66,68 & $3.116,0$ & 3,41 & 0,00 & 66,68 & 0,000 & 0,000 & 0,000 & 0,000 \\
\hline 36250000 & $2.167,5$ & 3,54 & 52,62 & $2.167,5$ & 3,54 & 0,00 & 52,62 & 0,000 & 0,000 & 0,000 & 0,000 \\
\hline 36270000 & $1.602,8$ & 3,24 & 76,55 & $1.602,8$ & 3,24 & 0,00 & 76,55 & 0,000 & 0,000 & 0,000 & 0,000 \\
\hline 36290000 & $1.789,0$ & 3,40 & 81,57 & $1.789,0$ & 3,40 & 0,00 & 81,57 & 0,000 & 0,000 & 0,000 & 0,000 \\
\hline 36470000 & $1.113,5$ & 2,43 & 77,09 & $1.119,5$ & 2,41 & 1,00 & 77,10 & 4,862 & 0,539 & 0,823 & 0,013 \\
\hline 36520000 & $1.220,7$ & 2,01 & 70,70 & $1.242,4$ & 1,98 & 1,56 & 70,73 & 10,577 & 1,778 & $-1,493$ & 0,042 \\
\hline 36550000 & 604,4 & 3,63 & 81,49 & 604,4 & 3,63 & 0,00 & 81,49 & 0,000 & 0,000 & 0,000 & 0,000 \\
\hline
\end{tabular}


Incorporação do Impacto da Rede de Reservatórios Superficiais Artificiais de Caráter Intranual na Modelagem Hidrológica Chuva-Vazão

logia foi utilizada no PERH-Ce (SRH, 1992) para definição das disponibilidades hídricas do estado. Assim, apesar de suas limitações, tais equações ainda são utilizadas com freqüência em levantamentos expeditos.

A análise da validade da metodologia de representação dos reservatórios intranuais e do comportamento do modelo hidrológico proposto foi realizada em três etapas: A) Intercomparação entre a eficiência dos ajustes na calibração utilizando o SMAPm e o modelo proposto SMAP-RPA, além da análise de sensibilidade do parâmetro " $h_{\mathrm{RPA}}$ "; $B$ ) Análise da representatividade dos valores " $h_{\mathrm{RPA}}$ " em diferentes cenários de açudagem em uma bacia hidrográfica e seus efeitos na eficiência do ajuste na calibração do SMAP-RPA; e C) Análise física do parâmetro " $h_{\mathrm{RPA}}$ ".

\section{RESULTADOS E DISCUSSÃO}

\section{A) Eficiência SMAPm e o SMAP-RPA}

Esse item trata da comparação entre a eficiência dos ajustes na calibração utilizando o SMAPm e o modelo proposto SMAP-RPA para a mesma série de dados, além de promover uma análise de sensibilidade do parâmetro " $h_{\mathrm{RPA}}$ ".

Foram realizados testes para verificação se a representação dos reservatórios superficiais artificiais através do reservatório matemático (RPA) promoveria um melhor ajuste entre os hidrogramas de vazões observadas e calculadas. A melhoria no ajuste mencionada é representada pelo aumento da medida de eficiência pela equação de Nash e Sutcliffe $\left(\mathrm{E}_{\mathrm{NS}}\right)$ com relação ao SMAPm e através da variação percentual dos valores absolutos dos parâmetros calibrados.

Devido ao fato de o modelo SMAPm apresentar-se como um subconjunto das rotinas de transformação chuva-vazão do modelo SMAP-RPA, espera-se que a eficiência dos ajuste dos hidrogramas apresentem valores maiores ou iguais aos determinados no SMAPm. Tal fato se confirmou nesta análise e os resultados são apresentados no Quadro 7.

Observa-se no quadro citado que 8 estações apresentaram valores ótimos da Função Objetivo com o parâmetro " $\mathrm{h}_{\mathrm{RPA}}$ " não nulo. Logo, em $44 \%$ das estações estudadas a parcela referente aos reservatórios superficiais artificiais foi contabilizada no processo de chuva-vazão. Podendo ser observado também o aumento da eficiência dos ajustes entre as series de vazões calculadas e observadas das referentes bacias. Nestas estações os valores de " $h_{R P A}$ " variam entre 1,00 e $55,78 \mathrm{~mm}$ o que equivalem a um conjunto de reservatórios reais com volume de armazenamento entre 4,862 a $19,649 \mathrm{hm}^{3}$, gerando um ganho na eficiência do ajuste entre 0,013 e 1,632\%. Já o parâmetro "Sat" apresenta uma variação entre 0,539 e 25,468\%; e o "PEs" uma variação entre 0,741 e $36,932 \%$.

Em 5 das oito estações citadas os valores calculados são inferiores aos valores teóricos representativos exclusivamente da pequena açudagem, tal fato pode ser explicado pelas incertezas da própria modelagem e da estimativa dos volumes dos pequenos reservatórios através de equações de regressão.

Em 56\% das estações estudadas a presença de reservatórios superficiais artificiais não influíram significativamente no processo de geração de vazões, fazendo com que o SMAP-RPA se comportasse como o SMAPm.

Como exemplo do comportamento da calibração dos modelos SMAPm e SMAP-RPA a Figura 4 apresenta os hidrogramas de vazões observadas e calculadas para estação 35650000. Os parâmetros "Sat" e "PEs" obtiveram uma variação absoluta de 5,8 e 9,8\%, respectivamente, entre os modelos analisados; e a eficiência medida por $\mathrm{E}_{\mathrm{NS}}$ obteve um pequeno aumento de $0,45 \%$. Apesar da pequena variação dos parâmetros e da eficiência na calibração o modelo SMAP-RPA conseguiu identificar um volume de pequena açudagem na bacia de $8,6 \mathrm{hm}^{3}$ o que equivale a um valor de $18,93 \mathrm{~mm}$ no parâmetro " $\mathrm{h}_{\mathrm{RPA}}$ ".

Portanto, comparando-se os valores estimado dos reservatórios intranuais através do modelo SMAP-RPA (Quadro 7) e os volumes armazenáveis calculados através das regressões de PERH-Ce (SRH, 1992) (Quadro 5), levando-se em considerações suas limitações, pode ser considerada realista a capacidade de armazenamento em pequenos reservatórios de bacia hidrográfica calculada a partir do modelo hidrológico SMAP-RPA.

Comportamento semelhante foi observado em todas as bacias onde o modelo SMAP-RPA conseguiu contabilizar o efeito da pequena açudagem nas bacias hidrográficas, mesmo na bacia 35760000 onde observa-se as maiores variações de "Sat", "PEs" e " $E_{N S}$ ". Por tanto, verifica-se que apesar da inclusão de um novo parâmetro no SMAPm a parcimônia deste modelo permanece praticamente inalterada, pois como afirmado anteriormente o uso do SMAPm ou SMAP-RPA varia de 2 para 3 os parâmetros a serem calibrados.

Ainda em relação a Figura 4, verifica-se o comportamento de enchimento e esvaziamento do reservatório RPA, apresentando armazenamentos 
máximos entre os meses abril-maio o que representa bem o comportamento físico da região onde aproximadamente $80 \%$ das precipitações se concentram nos 4 primeiros meses do ano, associados a altos níveis de escoamento superficial devidos ao solos rasos e o embasamento cristalino. Comportamento semelhante pode ser observado nas outras bacias em estudo.

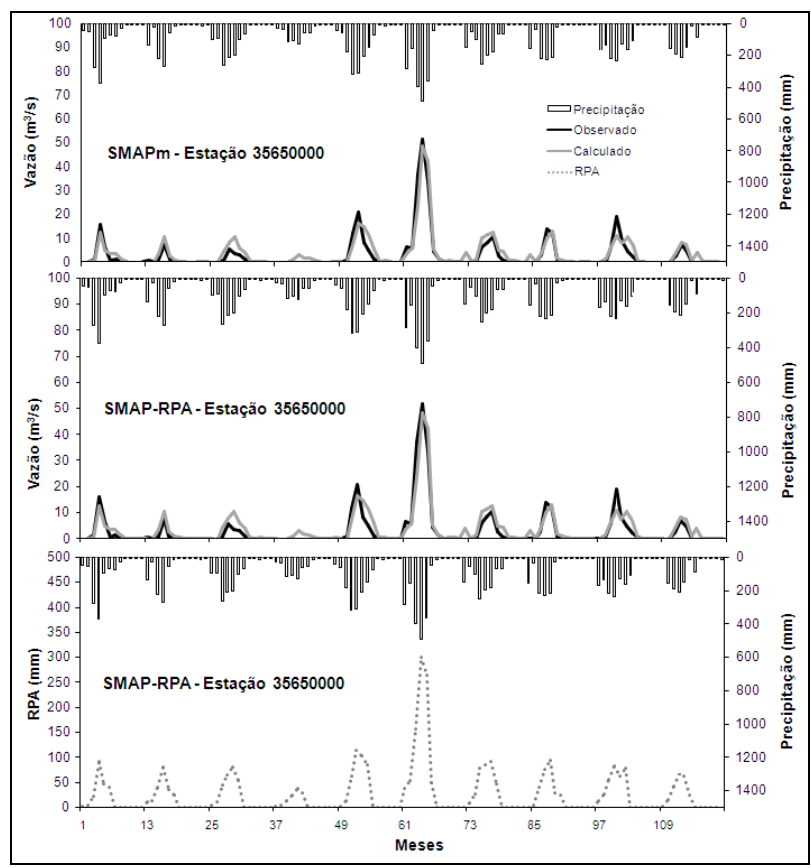

Figura 4 - Resultados de calibração do modelo SMAPm e SMAP-RPA; comportamento do reservatório matemático representativo da pequena açudagem - RPA.

Observa-se que pode-se assumir outras regras de operação para o reservatório que representa o efeito da pequena açudagem, sendo a formulação apresentada neste trabalho uma primeira aproximação. Este reservatório pode ser operado explicitamente como reservatório equivalente ao conjunto dos pequenos reservatórios. Há, porém, uma dificuldade adicional em regras mais complexas de operação destes reservatórios, qual seja, a definição das demandas que retiram o mesmo. A regra de operação aqui utilizada reconhece que estes reservatórios são de regularização intra-anual e impõe explicitamente esta condição aos mesmos. Sendo desta forma mais simples e robusta na representação dos efeitos das afluências no período chuvoso e as perdas por evaporação e demais retiradas no período seco.
Para análise de sensibilidade do parâmetro " $h_{\text {RPA }}$ " foram efetuadas otimizações dos parâmetros "Sat" e "PEs" para cada variação de " $h_{\text {RPA }}$ " e verificado a eficiência do ajuste. Os resultados desta análise de sensibilidade podem ser observados na Figura 5. A partir desta análise verifica-se que a eficiência na calibração do modelo varia de forma pouco significativa com relação às grandes variações do parâmetro " $h_{\text {RPA }}$ ", podendo este ser considerado pouco sensível as variações impostas ao modelo.

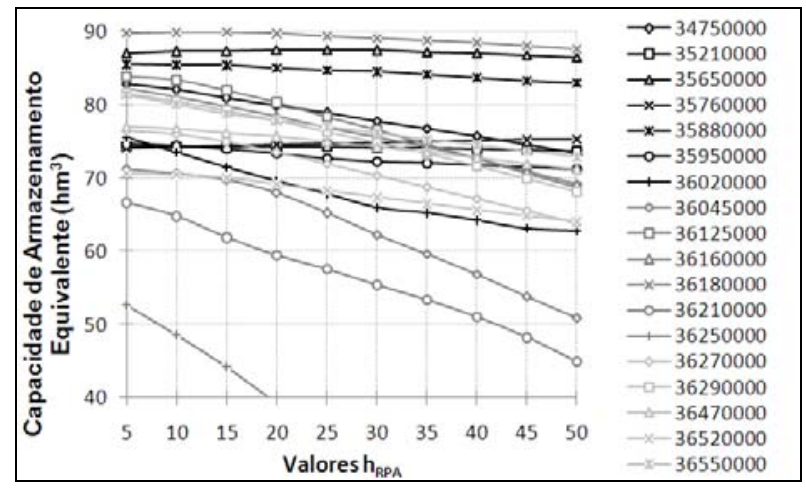

Figura 5 - Resultado da análise de sensibilidade do parâmetro " $h_{\mathrm{RPA}}$ " apresentando a variabilidade da eficiência do ajuste.

Ainda com relação a Figura 5, somente para estação 35760000 o ponto de máxima eficiência $\left(\mathrm{E}_{\mathrm{NS}}\right.$ $=75,36 \%$ ) não pode ser observado devido o valor a este valor ser equivalente a $u m h_{R P A}=55,78 \mathrm{~mm}$, portanto fora dos limites apresentados. No entanto, para não limitar a análise do leitor apresentam-se aqui os valores de: $h_{\mathrm{RPA}}=50 \mathrm{~mm}$ equivalente a $\mathrm{E}_{\mathrm{NS}}=75,34 \% ; \mathrm{h}_{\mathrm{RPA}}=55 \mathrm{~mm}$ equivalente a $\mathrm{E}_{\mathrm{NS}}=75,36 \%$ e $\mathrm{h}_{\mathrm{RPA}}=60 \mathrm{~mm}$ equivalente a $\mathrm{E}_{\mathrm{NS}}=75,35 \%$.

\section{B) Análise da representatividade do " $h_{\mathrm{RPA}}$ "}

Esse item trata da análise da representatividade dos valores " $h_{\mathrm{RPA}}$ " em diferentes cenários de açudagem em uma bacia hidrográfica e seus efeitos na eficiência do ajuste na calibração do SMAP-RPA.

Para esta análise o período de calibração do modelo foi separado em duas partes tendo como limite o ano de construção do primeiro reservatório estratégico caracterizando assim dois cenários, onde o Cenário 1 conta apenas com a intervenção de pequenos reservatórios e o Cenário 2 conta com a intervenção dos pequenos reservatórios acrescidos dos reservatórios estratégicos. Os resultados deste experimento podem ser observados no Quadro 8 para o Cenário 1 e 2. 
Incorporação do Impacto da Rede de Reservatórios Superficiais Artificiais de Caráter Intranual na Modelagem Hidrológica Chuva-Vazão

Quadro 8 - Resultados ótimos do ajuste do SMAP-RPA para o Cenário 1 e 2

\begin{tabular}{|c|c|c|c|c|c|c|c|c|c|c|c|c|}
\hline \multirow[b]{2}{*}{ Estação } & \multicolumn{6}{|c|}{ SMAP-RPA (pequena açudagem) - Cenário 1} & \multicolumn{6}{|c|}{ SMAP-RPA (reservatórios estratégicos) - Cenário 2} \\
\hline & $\begin{array}{c}\text { Sat } \\
(\mathrm{mm})\end{array}$ & $\begin{array}{l}\text { PEs } \\
\text { (ad.) }\end{array}$ & $\begin{array}{l}\mathbf{h}_{\mathrm{RPA}} \\
(\mathrm{mm})\end{array}$ & $\begin{array}{l}\mathbf{E}_{\mathrm{NS}} \\
(\%)\end{array}$ & $\begin{array}{c}\text { Vol.RPA } \\
\left(\mathrm{hm}^{3}\right) \\
\end{array}$ & Período & $\begin{array}{c}\text { Sat } \\
(\mathrm{mm})\end{array}$ & $\begin{array}{l}\text { PEs } \\
\text { (ad.) }\end{array}$ & $\begin{array}{l}\mathbf{h}_{\text {RPA }} \\
(\mathrm{mm})\end{array}$ & $\begin{array}{l}\mathbf{E}_{\mathrm{NS}} \\
(\%)\end{array}$ & $\begin{array}{c}\text { Vol.RPA } \\
\left(\mathrm{hm}^{3}\right)\end{array}$ & Período \\
\hline 34750000 & $1.376,4$ & 2,43 & 0,00 & 90,08 & 0,000 & 1965-1979 & $1.510,4$ & 2,17 & 0,00 & 77,48 & 0,000 & $1980-2005$ \\
\hline 35210000 & 752,0 & 2,13 & 11,96 & 70,88 & 19,649 & 1963-1979 & 938,3 & 2,32 & 0,00 & 78,48 & 0,000 & $1980-2006$ \\
\hline 35950000 & $1.566,3$ & 3,01 & 0,00 & 75,56 & 0,000 & $1970-1997$ & $1.377,8$ & 2,59 & 0,00 & 50,39 & 0,000 & $1998-2006$ \\
\hline 36020000 & 482,6 & 3,84 & 0,00 & 66,11 & 0,000 & 1936-1953 & 585,6 & 2,67 & 0,00 & 77,73 & 0,000 & 1954-1981 \\
\hline 36160000 & 500,2 & 4,65 & 0,00 & 69,07 & 0,000 & $1937-1953$ & $1.187,7$ & 2,77 & 0,00 & 87,85 & 0,000 & $1954-2006$ \\
\hline 36470000 & $1.126,4$ & 2,26 & 1,00 & 81,43 & 4,862 & 1921-1986 & $1.405,4$ & 2,69 & 0,00 & 44,86 & 0,000 & $1987-2005$ \\
\hline 36520000 & $1.794,2$ & 1,80 & 4,17 & 59,77 & 28,343 & $1912-1959$ & 778,6 & 2,41 & 0,00 & 78,58 & 0,000 & $1960-2005$ \\
\hline
\end{tabular}

$\mathrm{Na}$ análise do Cenário 1 as estações que apresentaram valores nulos de " $h_{\text {RPA }}$ " e continuaram com estes valores quando considerada a série somente sob influência da pequena açudagem. Já em termos de eficiência as estações 34750000 e 35950000 obtiveram ganho de eficiência em relação ao período total de calibração de $7,21 \%$ e $0,88 \%$ no $\mathrm{E}_{\mathrm{NS}}$, respectivamente; as estações 36020000 e 36160000 tiveram perda de eficiência em relação ao período total de calibração de $9,46 \%$ e $13,15 \%$ no $\mathrm{E}_{\mathrm{NS}}$, respectivamente. As estações $35210000 \mathrm{e}$ 36470000 permaneceram com valores de " $h_{\text {RPA }}$ " iguais aos calculados para a série completa de dados, no entanto a primeira teve perda de eficiência do ajuste em $3,49 \%$ e a segunda teve um ganho no ajuste de $4,33 \%$ no $\mathrm{E}_{\mathrm{NS}}$. Já a estação 36520000 obteve uma melhoria na representação da pequena açudagem em torno de $2,61 \mathrm{~mm}$ de " $h_{\mathrm{RPA}}$ " e no valor equivalente ao volume armazenado em reservatórios de $17,766 \mathrm{hm}^{3}$, no entanto houve uma perda de eficiência no ajuste de $10,96 \%$ no $\mathrm{E}_{\mathrm{NS}}$.

No Cenário 2 os valores ótimos de ajuste dos hidrogramas de vazões calculadas e observadas apresentaram valores nulos de " $\mathrm{h}_{\mathrm{RPA}}$ " com perda de eficiência nas estações 34750000,35950000 e 36470000 de 5,49, 24,29 e 32,24\% no $\mathrm{E}_{\mathrm{NS}}$, respectivamente. Já para as estações 35210000, 36020000, 36160000 e 36520000 houve ganho na eficiência de 4,11, 2,16, 5,63 e $7,85 \%$ no $\mathrm{E}_{\mathrm{NS}}$, respectivamente.

Com objetivo de analisar a sensibilidade do parâmetro " $h_{\text {RPA }}$ " em relação a eficiência do ajuste das séries de vazões calculadas e observadas para os Cenários 1 e 2 foi testada a variabilidade do parâmetro em questão de acordo com a metodologia utilizada no caso anterior. Os resultados desta análise de sensibilidade podem ser observados na Figura 6 referente aos Cenários 1 e 2.

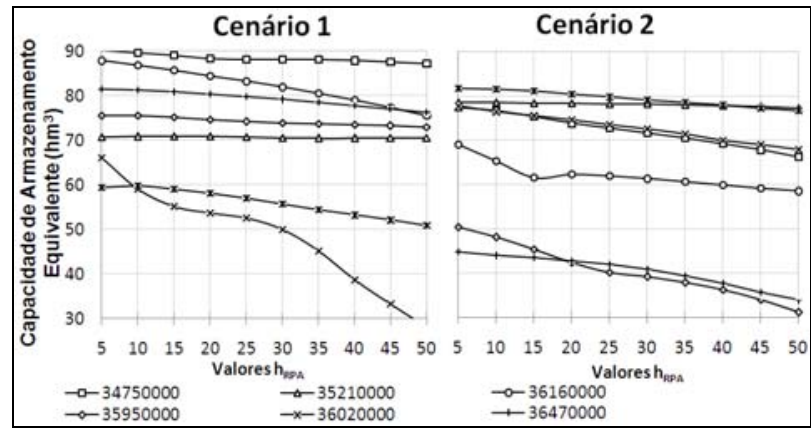

Figura 6 - Análise de sensibilidade do parâmetro " $h_{\mathrm{RPA}}$ " do SMAP-RPA em relação a eficiência dos hidrogramas observados e calculados para o Cenário 1 e 2.

Assim como na análise de sensibilidade do caso anterior, verifica-se que a eficiência na calibração do modelo varia de forma pouco significativa com relação às grandes variações do parâmetro " $h_{R}$ PA", podendo este ser considerado pouco sensível as variações impostas ao modelo.

Ainda com relação a análise de sensibilidade de " $h_{\text {RPA }}$ ", observa-se no Quadro 8 que a estação 35210000 um ponto de máxima eficiência $\left(\mathrm{E}_{\mathrm{NS}}\right.$ $=70,88 \%$ ) para um valor de $\mathrm{h}_{\text {RPA }}=11,96 \mathrm{~mm}$. A eficiência continua baixando até um " $\mathrm{h}_{\mathrm{RPA}}$ " próximo de $30 \mathrm{~mm}$ e começa uma curva ascendente até o valor ótimo local próximo ao $\mathrm{h}_{\mathrm{RPA}}=80 \mathrm{~mm}$ e $\mathrm{E}_{\mathrm{NS}}$ $=70,62 \%$, estes dados não podem ser observados no Quadro 8 pelos valores limites determinados.

\section{C) Análise física do parâmetro " $h_{\text {RPA }}$ "}

Buscando entender o padrão de comportamento do parâmetro " $h_{\mathrm{RPA}}$ " foi verificada a relação entre esta variável com diferentes características das bacias hidrográficas. A mais importante relação diz 
respeito a limitação de valores não nulos de " $h_{\mathrm{RPA}}$ " a bacias hidrográficas de menor porte como pode ser observado na Figura 7. Tal correlação possui base física, pois os pequenos barramentos estão em rios de primeira, segunda ou terceira ordem e localizados na parte alta bacia, onde o efeito da área não controlada por estes reservatórios é maior em bacias de maior porte.

A partir dos resultados observados identifica-se um importante efeito de escala, onde o efeito da pequena açudagem e conseqüentemente os ganhos no uso do SMAP-RPA se dá para bacias com área de drenagem inferiores a $5.000 \mathrm{~km}^{2}$. Para bacias com área superior a este valor $o$ " $h_{\mathrm{RPA}}$ " tende a zero e o SMAP-RPA se comporta como o SMAPm.

Assim retirando os valores nulos de " $h_{\mathrm{RPA}}$ ", foi feita uma nova verificação deste parâmetro com outras variáveis características das bacias hidrográficas. Cabe menção a exceção encontrada as bacias 35950000 e 36210000 , as quais mesmo possuindo áreas de bacias hidrográficas inferiores a $5.000 \mathrm{~km}^{2}$ (2.056 e $1.756 \mathrm{~km}^{2}$, respectivamente) possuem valores de " $h_{\mathrm{RPA}}$ " calculado iguais a zero, por tanto, a fim de não introduzir uma tendenciosidade na análise realizada a seguir estes valores também serão suprimidos.

A relação na escala logarítmica dos valores de " $h_{\mathrm{RPA}}$ " e da área da bacia hidrográfica é confirmada na Figura 8 com $h_{R P A}=10,576(A B H)^{-1,1833}$ e o coeficiente de correlação $\mathrm{R}=0,94$. Na Figura 9 utilizando como variável explanatória o volume escoado anual em hectômetros cúbicos na escala logarítmica temos $\mathrm{h}_{\mathrm{RPA}}=4,4599(\text { VEano })^{-1,6997}$ e $\mathrm{R}=0,79$. Na Figura 10 observa-se boa relação quando se usa a soma das áreas dos espelhos d'água da pequena açudagem contida na bacia hidrográfica. Com relação a área da bacia hidráulica defini-se aqui a pena açudagem como contendo área inferior a 100 ha. Neste caso a formulação é dada por $\mathrm{h}_{\mathrm{RPA}}=3,7804(\mathrm{SAEA})^{-1,0503} \mathrm{e}$ $\mathrm{R}=0,75$.

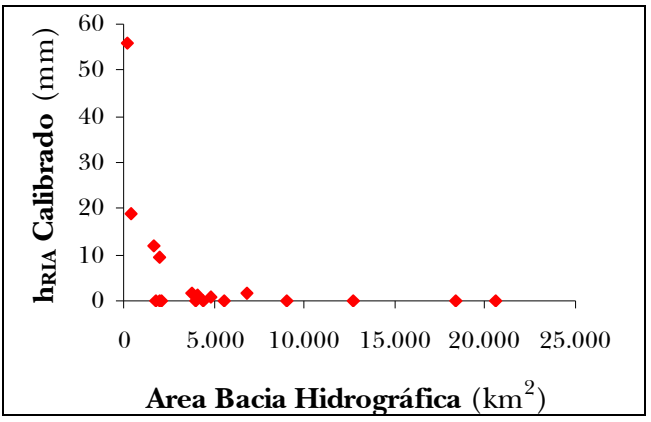

Figura 7 - Relação entre $h_{\mathrm{RPA}}$ calibrado e a Área da Bacia Hidrográfica (ABH) da estação fluviométrica.

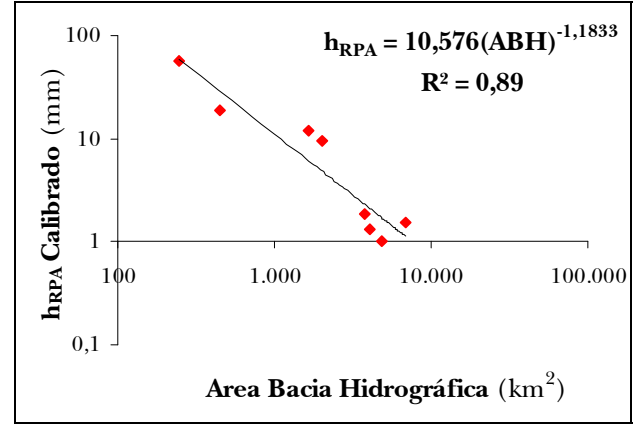

Figura 8 - Relação na escala logarítmica entre $h_{\mathrm{RPA}}$ calibrado e a Área da Bacia Hidrográfica (ABH) da estação fluviométrica.

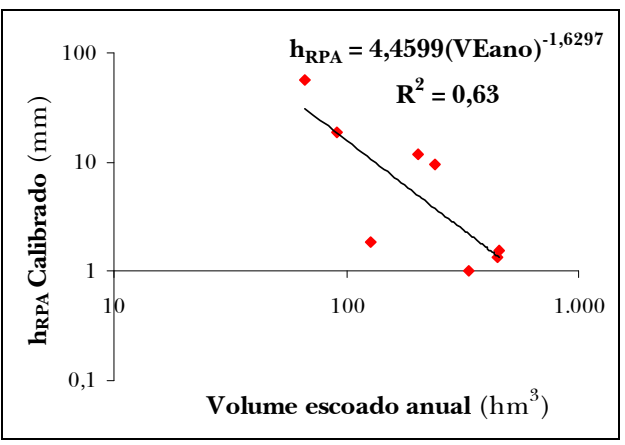

Figura 9 - Relação na escala logarítmica entre $h_{R P A}$ calibrado e o Volume Escoado Anual (VEano) na bacia hidrográfica.

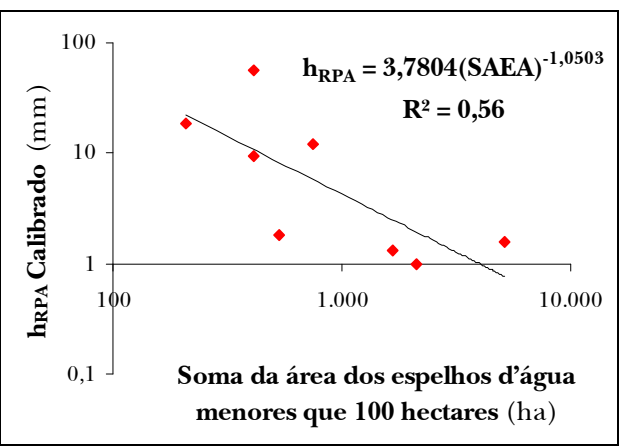

Figura 10 - Relação na escala logarítmica entre $h_{\text {RPA }}$ calibrado e a Soma das Área de Espelho d'Água (SAEA) menores a 100 hectares contidos na bacia hidrográfica.

Como a região de estudo possui coeficiente de escoamento médio nas bacias hidrográficas bastante parecidos o volume escoado tem uma relação direta com a área da bacia e a precipitação o que explica a boa correlação com o parâmetro " $h_{\mathrm{RPA}}$ ". Com relação a soma dos espelhos d'água da pequena açudagem percebe-se que o modelo tem uma 
dificuldade a mais de representar bacias com uma grande área de espelhos d'água. Assim, como a densidade de espelhos d'água da pequena açudagem nas bacias estudadas é bastante parecida, percebe-se novamente a questão da área da bacia hidrográfica explicando tal relação.

\section{D) Análise Global dos Resultados}

As bacias hidrográficas utilizadas neste estudo possuem um aumento do número de reservatórios construídos ao longo do tempo. Também é marcante o aumento da construção de reservatórios de médio e grande porte, os quais, devido seu caráter interanual podem ser considerados como estratégicos para o gerenciamento dos recursos hídricos.

A inserção de um reservatório matemático na rotina do SMAPm com a finalidade de representar os reservatórios superficiais artificiais contidos na bacia hidrográficas em questão nos leva a hipotetizar que a dimensão deste reservatório virtual representado pelo parâmetro " $\mathrm{h}_{\mathrm{RPA}}$ " possua valor compatível com a soma de toda pequena açudagem cadastrada na região e que aumentasse seu valor quando da inserção no tempo do impacto correspondentes a construção dos reservatórios estratégicos. No entanto, nenhuma destas hipóteses apresentou-se como verdadeira o que pode ser entendido pelas seguintes verificações.

O cálculo teórico de " $\mathrm{h}_{\mathrm{RPA}}$ " considera todos os reservatórios agregados e localizados imediatamente a montante da estação fluviométrica, neste caso todos os volume acumulado nestes reservatórios causariam um impacto negativo diminuindo assim a vazão medida na estação fluviométrica. No entanto, o que acontece fisicamente na bacia é que somente parte dos reservatórios trará algum impacto nas características do hidrograma dependendo da localização e o tamanho dos reservatórios. Por tanto, os valores do " $h_{\mathrm{RPA}}$ " calibrado sempre será menor ou igual ao valor teórico estimado.

Analisando os valores calibrados do parâmetro " $h_{\mathrm{RPA}}$ " verifica-se uma estreita correlação com a área da bacia hidrográfica em questão. Onde os valores de " $h_{\mathrm{RPA}}$ " não nulos são observados nas bacia hidrográficas de menores dimensões. Assim, a afirmação que tal parâmetro é relevante para bacias menores possui base física, pois os pequenos barramentos estão em rios de primeira, segunda ou terceira ordem e localizados na parte alta da bacia, onde o efeito da área não controlada por estes reservatórios é maior em bacias de maior porte.

O reservatório virtual RPA, de acordo com sua regra de operação, limita-se a representar ape- nas a pequena açudagem, tal fato é confirmado quando se verifica que o parâmetro " $\mathrm{h}_{\mathrm{RPA}}$ " calibrado para todo a série de dados sob a influência de grandes e pequenos reservatórios se assemelha aos valores calibrados quando utilizado parte da série de vazões anteriores a construção de reservatórios de grande porte. Quando se usa somente a parcela da série de vazões sob o impacto de reservatórios estratégicos verifica-se que o reservatório RPA perde sua funcionalidade devido aos valores nulos de " $h_{\mathrm{RPA}}$ " calibrados, a não representação da parcela relativa a pequena açudagem nestes caso nos leva a crer que os grandes reservatórios mascarem os resultados.

\section{CONCLUSÃO}

A geração de séries de vazões, utilizando modelagem hidrológica, em locais com alto grau de saturação de reservatórios superficiais artificiais exige uma análise diferenciada com o uso de modelos de transformação chuva-vazão que levem em consideração o efeito causado por estes reservatórios na geração dos deflúvios da bacia em estudo.

A inserção de um reservatório matemático com as características de operação representativas do comportamento da pequena açudagem do ambiente semi-árido, com a altura desse reservatório virtual sendo um parâmetro calibrável $\left(\mathrm{h}_{\mathrm{RPA}}\right)$, vem a ter uma representação mais realista da física destes processos sem comprometer a parcimônia do modelo original.

Sendo o SMAP-RPA uma ampliação do modelo SMAP em sua versão mensal, os resultados obtidos utilizando as bacias de contribuição de 18 estações fluviométricas localizadas no Estado do Ceará apresentou, como era de se esperar, ganho na eficiência do ajuste entre as séries de vazões observadas e calculadas para as bacias com " $\mathrm{h}_{\mathrm{RPA}}$ " não nulo $\mathrm{e}$ comportamento idêntico ao do SMAPm quando tal parâmetro é igualado a zero.

No entanto, o ganho de eficiência na calibração apesar de pequeno, assim como a variação nos parâmetros calibráveis "Sat" e "PEs", o modelo SMAP-RPA conseguiu identificar de forma bastante realista a capacidade de armazenamento em pequenos reservatórios das bacias hidrográficas onde o " $\mathrm{h}_{\mathrm{RPA}}$ " é não nulo.

De acordo com as análises do comportamento do parâmetro " $h_{\text {RPA }}$ " verificou-se que este apresenta pouca sensibilidade em termos de variabilidade do coeficiente de Nash-Sutcliff diante das grandes variações de " $h_{\mathrm{RPA}}$ " imposta ao modelo. 
Verificou-se uma estreita relação entre o parâmetro " $\mathrm{h}_{\mathrm{RPA}}$ " e a área da respectiva bacia hidrográfica. Os valores de " $h_{\mathrm{RPA}}$ " não nulos são observados nas bacia hidrográficas com área inferiores a $5.000 \mathrm{~km}^{2}$.

Assim, verificou-se que a medida de tal parâmetro é relevante para bacias de menor porte. Tal afirmação possui explicação física, pois os pequenos barramentos estão em rios de primeira, segunda ou terceira ordem e localizados na parte alta bacia, onde o efeito da área não controlada por estes reservatórios é maior em bacias de maior porte.

Portanto, os autores aconselham a utilização deste modelo, pois com o acréscimo de um parâmetro na calibração automática pode-se avaliar a interação da pequena açudagem com a geração de deflúvios em uma bacia hidrográfica e caso este parâmetro venha a possuir valor calibrado nulo não há perda na eficiência e representatividade dos resultados com relação a versão original do modelo.

Como recomendação para ampliação deste assunto em trabalhos futuros sugere-se a análise da representação na modelagem hidrológica dos reservatórios de médio e grande porte submetidos a uma sazonalidade marcante em termos de precipitação e altos índices de evaporação.

\section{AGRADECIMENTOS}

Os autores agradecem à FUNCAP - Fundação Cearense de Apoio ao Desenvolvimento Científico e Tecnológico pelo apoio dado ao Pós-DEHA Programa de Pós-Graduação do Departamento de Engenharia Hidráulica e Ambiental da Universidade Federal do Ceará, e a concessão de bolsa de doutorado em Engenharia Civil com Área de Concentração em Recursos Hídricos para o primeiro autor.

\section{REFERÊNCIAS}

ALEXANDRE, A. M. B. "Regionalização de Vazões Máximas, Médias e Parâmetros de Modelos Hidrológicos no Estado do Ceará”. Dissertação de Mestrado em Engenharia Civil com Área de Concentração em Recursos Hídricos da Universidade Federal do Ceará. Fortaleza. 2005.

CARVALHO, T.L.L.; e REIS Jr., D.S.R. "Avaliação da Influência dos Dados de Evapotranspiração Potencial no Desempenho de Modelos Hidrológicos em
Bacias do Semi-Árido Cearense". In: Anais do IX Simpósio de Recursos Hídricos do Nordeste. Salvador. 2008.

FUNCEME. "Mapeamento dos Espelhos D'Água do Brasil". Fundação Cearense de Meteorologia e Recursos Hídricos. Fortaleza. 2007.

INMET. "Normais Climatológicas (1961-1990)". Instituto Nacional de Meteorologia. Brasília-DF. 1992.

LOPES, J.E.G.; BRAGA JR., B.P.F.; CONEJO, J.G.L. "Simulação Hidrológica: Aplicações de um Modelo Simplificado". In: Anais do III Simpósio Brasileiro de Recursos Hídricos, v.2, 42-62, Fortaleza, 1981.

NASH, J.E. e SUTCLIFFE, J.V. "River Flow Forecasting Through Conceptual Models, Part I - A Discussion of Principles". Journal of Hydrology, 10, 282$290,1970$.

PAYAN, J.-L.; PERRIN, C.; ANDRÉASSIAN, V.; MICHEL, C. "How Can Man-made Water Reservoirs be Accounted for in a Lumped Rainfall-runoff Model?" Water Resources Research, 44, W03420, doi:10.1029 /2007WR005971. 2008.

SRH-CE. "Plano Estadual de Recursos Hídricos". Secretaria dos Recursos Hídricos do Ceará. Fortaleza. 1992.

WAGENER, T.; WHEATER, H.S. E GUPTA, H.V. "Rainfall-runoff Modelling in Gauged e Ungauged Catchments”. Imperial College Press, London. 2004.

\section{Incorporation Of The Annual Impact Of A Network Of Superficial Artificial Reservoirs On Hydrological Modeling Of Rainfall-Runoff}

\section{ABSTRACT}

A hydrologic model's ability to describe the processes encompassing the transformation of precipitation into flow rates depends on the assumptions, structure and formulations it uses. Models of the spatially distributed type are very attractive. However, the mathematical simplifications used may generate errors when the represented basin's features are very heterogeneous due to natural characteristics or to anthropic activity. The river regime in the semiarid Northeast of Brazil has undergone changes due to the construction of superficial artificial reservoirs, most of 
Incorporação do Impacto da Rede de Reservatórios Superficiais Artificiais de Caráter Intranual na Modelagem Hidrológica Chuva-Vazão

which are small reservoirs of an intra-annual nature. Those small reservoirs make modeling difficult.

In this paper we propose a change to the structure of the SMAP model aiming to explicitly incorporate the representation of small damming. This representation is done by inserting a reservoir into the mathematical model with the operating characteristics which are representative of small damming behavior. The dimension of that reservoir is a gradable parameter $\left(h_{R P A}\right)$ aiming to identity the effect of this intra-annual regularization.

The proposed model, SMAP-RPA, consists of expanding the SMAP model in its monthly version. Therefore, determining the results from the RPA component improves the model's performance and makes it more realistic when compared to SMAPm's performance. As a result, in cases where the dams in the hydrographic basin do not produce significant variation in the hydrograph, the " $h_{R P A}$ " parameter is null and the SMAP-RPA operation is the same as in SMAPm. Aiming to ascertain the proposed model's validity, we developed a case study by formulating two scenarios according to the flow rate series and the characteristics of 18 hydrographic basins located in the state of Ceará. The results support the efficiency of small damming representation and the ensuing efficiency improvement in the adjustments to observed and calculated series. In this paper we have also noticed an important scale effect. The basins which were affected most by small damming were those with a drainage area of less than 5,000 km2. The impact of this small damming on larger scale basins is not detected by the model, which makes the " $h_{R P A}$ " parameter null.

Key-words: hydrological modeling; intra-annual reservoirs; SMAP-RPA 